\title{
Exploring plasticity in the development path of the automotive industry in Baden-Württemberg: the role of combinatorial knowledge dynamics
}

\begin{abstract}
Profound insights into why some regional paths remain dynamic over several decades while others follow a bumpy road and become stuck in the past are still scarce. This paper addresses this gap by contributing to a deeper understanding of dynamics within territorial paths. It focuses on organizational and institutional changes connected with so-called combinatorial knowledge dynamics. We claim that especially innovations based on the transversal combination of separated knowledge bases are connected to the gradual transformation, recombination or creation of institutions at the microlevel. This contribution explores the dynamics within the automotive industry of Baden-Württemberg by providing a meso-level overview of the trajectory of its technological and institutional development as well as an analysis of a case study that illustrates the gradual institutional change on the micro-level in the course of knowledge combination
\end{abstract}

Keywords: innovation biography, institutional change, path plasticity, knowledge dynamics

\section{Introduction $^{1}$}

Why do some regions become victims of their former success, while others continue to thrive, even though they are characterized by agglomerations of the same industry? A particularly striking example for this contrasting development is provided by the automotive regions Detroit (USA) and Baden-Württemberg (Germany). Whereas the former provides textbook examples for industrial decline and all its devastating impacts on urban and socio-economic developments, the latter has been continuing to master several crises in the last decades. In this contribution, we argue that dynamics within the development path of Baden-Württemberg's automotive industry is achieved because actors in Baden-Württemberg's automotive industry are able to successfully explore path plasticity and drive combinatorial knowledge dynamics.

The concept of path plasticity is used to set the focus on the continuity of dynamic change within paths. At the territorial as well as at the organizational level there are barriers to - and opportunities for - innovation and knowledge dynamics within paths which are only partially understood and not acknowledged in detail within the different strands of innovation literature (STRAMBACH/ HALKIER 2013). To explore both the plasticity and dynamics within paths the institutional and organizational dimensions are essential as they explain stability and change of development trajectories.

While substantial insights are developed in mechanisms producing stability of paths such as institutional complementarities, a process theory that may explain why some paths remain dynamic over a long time, while others become victims of their former success (HASSINK 2010; GRABHER 1993), has not been developed yet. Profound insights onto how the dynamics enfold beyond stabilization are still scarce. Therefore the paper aims at contributing to a deeper understanding of dynamics within territorial paths by focusing on organizational and institutional changes connected with combinatorial knowledge dynamics. We argue that especially these innovations based on the combination of knowledge from different originally separated knowledge bases are often interconnected with the transformation, recombination or creation of institutions at the micro-level, as they have imply coping with many different cognitive, technological, organizational and institutional interfaces. Hence, in these knowledge exploration processes many barriers have to be overcome caused by different forms of distance (BOSCHMA 2005; IBERT 2010; Knoeben/Oerlemmans 2006) and a low degree of institutional overlaps. In the bridging of these barriers, combinatorial knowledge dynamics 
have the potential to generate variety and diversity of organizational forms and organizational routines that may in a direct or indirect way foster dynamics within an established path.

The empirical investigation focuses on BadenWürttemberg's automotive industry and comprises two parts, located respectively on the meso- and on the micro-level. At first, there is an overview on the regional development path of the automotive industry. Despite undergoing several crises in global change, the path of the industrial sector can be characterized as longterm competitive, showing adaptive dynamics within the path. The second part is set on the micro-level and closely examines an innovation based on combinatorial knowledge dynamics.

In order to do so, the second part specifies combinatorial knowledge dynamics related to innovation and differentiates them from cumulative ones. In the following section the relation of combinatorial knowledge dynamics to the creation and transformation of organizational routines is elaborated on. After stating three research-guiding questions, the development path of Baden-Württemberg's automotive industry is presented in part four. Following a short introduction of the applied methods, in part six the empirical analysis on the micro-level shows in one case study how combinatorial knowledge dynamics are carried out. In the last section, these conceptual and empirical results are reflected upon.

\section{Combinatorial knowledge dynamics and path plasticity}

The notion knowledge dynamics is being used recently in the field of research focusing on knowledge economics. In the following we distinguish combinatorial knowledge dynamics from cumulative ones by their organizational and institutional characteristics and discuss their relationship to the plasticity of established technological and institutional development paths.

Knowledge dynamics on the micro-level emerge through the interactions of actors within organizations and between organizations contributing to innovation. Hence interaction processes among actors are central to the use and creation of knowledge and its transformation into innovations with economic value added. Drawing on the literature on knowledge economics, it becomes obvious that three factors affect knowledge dynamics in a generic way: the specific knowledge base of agents, their competencies or capabilities (AMIN/COHENDET 2004; MALERBA/ ORSENIGO 2000; Dosi/Faillo/MARENGO 2008) and the context in which these processes take place (STRAMBACH 2008).

Knowledge is a contested concept. In our understanding knowledge constitutes a capacity for action (STEHR 1994). Knowledge does not easily flow like information due to its inherent tacit dimension, its process character and its context dependence as identified by the theory of knowledge economics (Foray 2004; Polanyi 1985; NoOTEBOOM 2010). The commodification of knowledge is fundamentally grounded in complex social processes (BERGER/LUCKMANN 1966; STEHR 1994) and involves multifaceted communication and learning between the involved actors.

In evolutionary economic theory the cumulative nature of knowledge that leads to the formation of specific knowledge bases is widely acknowledged. The discourse on the need to differentiate further cumulative knowledge bases started only recently in economic geography. In the SAS taxonomy, three types of knowledge bases are distinguished: the synthetic, analytical and the symbolic (ASHEIM 2007). The main characteristic of this taxonomy is that knowledge types are not defined by their content or value, but by "the approaches to how, and principles of reasoning through which, knowledge is developed and by the criterion for evaluating the value and usefulness of this knowledge" (MANNICHE 2012, 2). Hence, using this taxonomy puts emphasis on organizational routines and institutions affecting the creation, transfer, transformation and exploitation of knowledge and their different significance in various industries. Even though this relatively new conceptual approach is not yet a complete one, its emphasis of institutional differences between knowledge bases is useful for the distinction between cumulative and combinatorial knowledge dynamics.

According to SCHUMPETER (1934), it could be argued that innovations are always new combinations of existing knowledge and learning. Consequently, combination is considered in general as an essential source for novelty, innovation and technological change. However, using an institutional approach, knowledge dynamics that lead to innovation can be differentiated regarding 
their organizational and institutional characteristics. Not all types of knowledge exploration and exploitation processes generate the same need for institutional change. In innovation research the widely used differentiation between radical and incremental innovation points also in this direction assuming that radical innovation are often connected with the creation of new institutional settings.

The special feature of cumulative knowledge dynamics is that the production of new knowledge is directly dependent or builds mainly on previously generated knowledge bases structured over time by co-evolved functionally specialized institutional settings. Even in cumulative knowledge dynamics, actors may combine several specialized knowledge bases, too. However, for this kind of combinations the functional institutional settings in which the respective knowledge stocks are embedded are similar or have at least a very high degree of overlapping (for more detailed information to cumulative and combinatorial knowledge dynamics see STRAMBACH/ KLEMENT 2012). In cumulative knowledge dynamics actors share a certain degree of overlapping institutional settings that facilitate knowledge exploration and exploitation processes.

Institutional settings are believed to emerge and co-evolve with innovation processes, contributing to knowledge accumulation and competence building due to both their constraining and their enabling functions (CAMPBELL 2011) which in turn affect the continuity and stability of paths. Moreover the innovation potential of prevailing institutions allows and makes a certain variety of changes likely to be generated (PELIKAN 2003, 255).

The specific characteristic which differentiates combinatorial knowledge dynamics from cumulative ones is their transversal nature. They come into existence by the unification of originally separated knowledge bases that provide distinct institutional settings. These knowledge bases may be placed in different technologies, sectors, organisations or territories (CREVOISIER/ JEANNERAT 2009; HalKier 2012; StrambaCh/ KLEMENT 2012). Hence, interaction in combinatorial knowledge dynamics implies coping with many different cognitive, technological, organizational and institutional interfaces to overcome barriers caused by different forms of distance. In knowledge exploration and knowledge sharing processes such knowledge interactions have to bridge various intra- and inter-organizational institutions. In turn, these boundaries and the lower degree of overlapping institutional settings affect and limit combinatorial knowledge production. Diversity, an important precondition and stimulator for creativity and innovation simultaneously causes misunderstandings and barriers in knowledge sharing and transforming processes at the micro-level (Boschma 2005; CARlile 2004; NoOteboOm 2010).

Given the transversal nature of combinatorial knowledge interactions, they may often involve the transfer of institutions to different contexts, or rearrangements or re-combinations of institutional principles and social practices in new and creative ways for new purposes. Developed institutional settings of paths by no way determine behaviour of actors. There is always a degree of plasticity even under constraint choices of a path which can be explored by creative and reflexive actors (StRAmbach/HaLkiER 2013). Path plasticity hereby should not be mistaken as the result of high adaptive dynamics within paths. The concept refers on a feature of development paths: the constrained changes and mechanisms leading to dynamics within paths. Path plasticity provides a certain scope for variation within a well-established institutional setting of a path. This characteristic of paths is rooted in the interpretative flexibility of institutions and incoherence of paths themselves due to the interconnectedness of institutional settings at different levels. The notion of path plasticity does not deny the development of path-dependent trajectories, but draws attention to the fact that institutional settings also provide a scope for action that can be explored by creative agents, for instance by new recombination, reinterpretation or redeployment of institutions.

Thus, taking into account path plasticity allows for a novel perspective on the development of regional development paths. Whereas in the debate on path dependency, negative lock-ins and the de-locking of paths by disruptive breakthroughs are emphasized, the notion of path plasticity focuses on the continuity of dynamic change, the relation between continuity and change and the gradual change of institutional settings (STRAMBACH/HALKIER 2013 in this issue).

We argue that actors participating in combinatorial knowledge dynamics - intentionally or unintentionally - explore path plasticity by overcoming small institutional overlaps, these know- 
ledge dynamics have the potential to enhance the scope of variety within an established path not only through the creation of new knowledge but also by the creation of new organizational forms. The latter might challenge the innovation absorptivity of institutions (PELIKAN 2003) and produce a need to change, even if only in a gradual way and in more peripheral institutional arenas of a path. However, following the reasoning of gradual institutional change, combinatorial knowledge dynamics may contribute to modes such as layering, conversion or drift and add over time as well to substantial transformative change of basic path specific institutions (MAHONEY/THELEN 2010).

\section{Organizational routines and combina- torial knowledge dynamics}

Knowledge dynamics emerge and are founded in interactions processes of actors within firms and other organizations or between networks of firms and organizations. The micro-level of actors is an important analytical level to deepen the understanding of dynamics within paths and the territorial shaping of combinatorial knowledge production behind innovation. Since firms and organizations are highly responsive to shifts in the economic environment, they are central actors for initiating institutional change. To gain a more profound understanding on what limits and enables knowledge sharing in combinatorial knowledge dynamics, it is worth to take a more detailed look on organizational routines.

While the term routines is mainly treated as black-boxes in evolutionary economics and evolutionary economic geography and applied in a passive way by explaining variety and selection processes (Dosi/Faillo/Marengo 2008; KINDER/RADWAN 2010; Strambach/HalKier 2013), organizational theory however focuses on the purposeful change and creation of routines by active agents. In the latter there is no unified definition of organizational routines as the term is used for referring to both behavioral and cognitive regularities (BECKER 2004). Yet they are essential institutions that coordinate and integrate knowledge using and exploring processes by establishing cognitive proximity among individual actors and communities at the firm level. Furthermore they also link firms with their environment over time. At the micro-level of actors knowledge interaction processes are strongly influenced by cognitive distance and proxim- ity between them (Boschma 2005; NoоTEвоOM 2010; IBERT 2010) since knowledge and sense making are embedded in action contexts. Cognitions ${ }^{2}$ determine perceptions and interpretation and judgments of situations. Actors located in similar institutional settings, for instance within an organization, can share views, interpretations, values and norms of behaviour which are not shared outside the organization. Based on organizational routines firms provide cognitive orientation and foster cumulative knowledge dynamics and cumulative competence building (Nooteboom 2010). As Grant (1996) points out, routines provide a mechanism for coordination which does not require the communication of knowledge in explicit form.

Furthermore, organizational routines also link firms with their environment. They cannot easily be replicated and transferred to other contexts (TEECE 2010) due to their collective and processual nature. As a collective outcome, they reflect social practices and localized learning processes at a certain point in time. The knowledge and competence-based theory of the firm (KOGUT/ ZANDER 1992; NonAKA/TAKeuchi 1995; TeECE et al. 1997) recognizes the weight of path dependencies of knowledge and organizational practice inherited from the past.

From an evolutionary perspective the unreliability of routine imitation and the combinatorics of routines are considered as a major source of novelty (BECKER/KNUDSEN/MARCH 2006; Boschma/Frenken 2011). Compared to cumulative knowledge production, the development of organizational routines and governance structures which are capable to coordinate and govern combinatorial knowledge creation processes seems to be far more complex. Combinatorial knowledge dynamics are characterized as action contexts with the participation of a variety of different actors who belong to different organizations, industries or are located in different places. This transversal nature of combinatorial knowledge production is closely connected with more institutional diversity.

Substantial insights at the aggregated level of industries and technologies exist, showing that sector specific institutions, established practices and organizational routines differ considerably (Malerba 2005; PavitT 1984). Marked sector differences of organizational routines related to knowledge creation, transfer and evaluation are made clear in research using the SAS typology 
of knowledge types, which identifies synthetic, analytic and symbolic knowledge bases (AsHEIM 2007; AsHeim/COENEN 2006). Even though this taxonomy does not yet represent a complete concept and still lacks a thorough distinction of its three types, it remains very valuable for the analysis of combinatorial knowledge dynamics. Other than alternative taxonomies of knowledge, the SAS taxonomy acknowledges that different knowledge types make use of different organizational routines for their creation, transformation, evaluation and use based on their epistemological properties (MANNICHE 2012). Based on these insights and compared to cumulative knowledge production both a high degree of cognitive diversity and a low level of common knowledge among the actors can be considered as characteristic attributes of combinatorial knowledge production.

Given that institutional settings impact selection processes in the exploration of knowledge complementarities, and facilitate the exploitation, boundaries might be caused by cognitive distance, a low degree of institutional overlaps and the required overcoming of other forms of relational distance (IBERT 2010). Particularly as the efficiency of knowledge integration is influenced by the level of common knowledge, the frequency and variability of the activity and the structure, which economizes on communication (GRANT 1996; Kogut/Zander 1992). Actors coming from a variety of backgrounds have to invest much more in cognitive coordination and establishing sufficient mutual understanding in order to explore complementarities of originally separated knowledge bases. The plasticity of institutions understood as their interpretative flexibility and the low degree of institutional coherence open up a wide room for divergent interpretations and perceptions (STRAMBACH/HALKIER 2013). In turn, that generates the need for complex communication processes to convert the variety of different actors' meanings into shared views. The latter enable the ability to collaborate and influence the willingness and commitment to do so (NoоTевоom 2010, 77).

Building upon the knowledge based view of the firm, it is obvious that actors in such action contexts have to invest in establishing mutual understanding, e.g. by rearranging, transferring, reinterpreting or creating organizational routines (StRAMBACH/KLEMENT 2012). In turn, it can be assumed that combinatorial knowledge dynamics pose several challenges that innovat- ing actors can only meet when they overcome these before-mentioned boundaries. Combinatorial knowledge dynamics have the potential to generate variety and diversity of organizational forms and organizational routines and contribute to institutional change.

Hence our research is guided by these questions: To what extent does the institutional setting of the region provide potential resources for actors to conduct combinatorial knowledge dynamics? How do actors overcome the boundaries implied by combinatorial knowledge dynamics? Finally, do combinatorial knowledge dynamics on the micro-level lead to gradual change in the regional institutional setting?

\section{Institutional changes in the regional trajectory of the automotive industry of Baden-Württemberg}

Being home to the inventor of the automobile, Baden-Württemberg has evolved as one of Europe's most important cluster of the automotive industry. Besides the original equipment manufactures (OEM) Daimler, Porsche and $\mathrm{Au}$ di (belonging to the Volkswagen Corporation) a variety of suppliers (e.g. Robert Bosch, $Z F$ Friedrichshafen, Mahle, Behr) and engineering service providers (e.g. Bertrandt) are located there, especially in the Stuttgart region. A strong knowledge base in the synthetic knowledge domains of automotive, mechanical and electrical engineering has formed (ASHEIM/GERTLER 2005).

The automotive industry's success can be counted as one of the major factors for the long-lasting economic success of Baden-Württemberg since the 1950s. In about 3000 enterprises across the whole value chain a turnover of 91.91 billion Euro was generated in 2009. Yet the successful history of the automotive industry in BadenWürttemberg was not as predictable and steady as one may assume. After an especially prosperous post-war era it faced several challenges and adversities since the early 1990s (HAWLITSCHEK 2011).

Baden-Württemberg's automotive industry managed to cope with manifold challenges over the last 20 years, recovered in relative short time spans and is still going strong. The all-time high of the industry's turnover, 133.3 billion Euro, was reached in the last pre-crisis year of 2007 
(HAWLiTSCHEK 2011). Even the current economical crisis has not had a big negative impact: The number of employees (198958) in BadenWürttemberg's automotive industry has already been slightly higher $(+4195)$ in June 2012 than in December 2008 before the crisis (Statistik der Bundesagentur für Arbeit 2012; hereby the number of employees in NACE Rev.2 division 29 represent employees in the automotive industry).

A wide theoretical and empirical literature places emphasis on the advantageous effects of the long-established organization of the technologybased synthetic knowledge production and diffusion in the region for the innovativeness and competitiveness, particularly its established numerous interfaces, linkages and overlaps between science, economy and policy. Mainly four dimensions of the institutional setting have been identified that determined the industrial technology- and science-based innovation profile responsible for the long-term competitiveness of the regional automotive industry.

- The regional research infrastructure and the specialization profile of the scientific system largely correspond to the industrial technology and the technological fields of the researchand-development-intensive core industries: automotive, mechanical engineering and electronics.

- Complementary institutional configurations in the scientific system provide a great potential of highly skilled human resources in the technological fields of synthetic and analytical knowledge bases.

- The occupational training and higher education system are closely linked to the skill and knowledge requirements of the core industries.

- Since the 1980s, a decentralized technology transfer structure for small and medium sized enterprises facilitates knowledge exchange and knowledge generation in applied synthetic knowledge fields (BEACZYK/SCHIENSTOCK/ SteFFENSEN 1996; HeIDENREICH/KRAUS 1998).

These institutional settings with the intersection of the specific labour market institutions which characterize the German coordinated market economy (e.g. CASPER et al. 2005) foster firms' investments in human capital and contribute to cumulative competence building of firms the important basis for innovative developments.

This co-evolved institutional setting that brought success in the previous 40 years faced several new challenges since the early 1990s: The new global flexibilization of production systems, the growing importance of non-European markets, changing consumer demands towards new market segments (e.g. minivans, small cars, SUV, growing consumer awareness of environmental and sustainability issues and stricter environmental regulations. Furthermore, German automotive companies tended to overlook the value of non-technological types of innovations, such as organizational and service innovations (BRACZYK/SCHIENSTOCK/STEFFENSEN 1996). As the institutional setting was geared to support synthetic knowledge creation, symbolic knowledge bases were underdeveloped. Empirically reflected by the comparatively low share of service industries, particularly of media and knowledge-intensive business services in the regional economy, it became obvious that the stable, well established, institutional settings of BadenWürttemberg had caused rigidities and lock-in effects (cf. COOKE/HEIDENREICH/BRACYZK 2004; Fuchs/WASSERMANN 2005; StrambaCH 2002).

Employment losses and economic downturn raised awareness by political and economic actors alike who took action in several ways. Hence, in the following years various economic and institutional restructuring processes could be observed in the region as intended or unintended outcomes of multi-actor initiatives. By regarding these initiatives from the perspective of knowledge policies, we argue these are geared towards fostering combinatorial knowledge dynamics and contributed to gradual institutional change by opening up related variety (BoschMA/ FRENKEN 2011) in the path of the automotive industry. In the following, we shed light on some examples for multi-actor initiatives that are geared towards fostering combinatorial knowledge dynamics mainly in two fields: the support of cross-sectoral networks and organizations and the extra-regional knowledge sourcing.

\section{Cross-sectoral networks and organizations}

Since the mid-1990s policy measures have been focusing on promoting bottom-up initiatives and self-organizing processes, and the increasingly multi-level nature of policy design and implementation is noticeable. Political actors 
in Baden-Württemberg recognized that the underdeveloped knowledge intensive business services (KIBS) industry had potential value to the region's industrial core and supported it with the creation of new organizations to support complementary service industries in the information technology (IT) and media sector (KRAUSS 2008; Strambach 2012). Several publicly or privately funded sector organizations, e.g. $M F G$ Innovationsagentur für IT und Medien and business networks (bwcon), foster the knowledge transfer and the use and application of IT knowhow in Baden-Württemberg, aiming to intensify the exchange between research, educational organizations, software firms and customer sectors by maintaining a series of events, congresses, workshops and cluster initiatives (FUCHS/WASSERMANN 2005).

Regarding regional policy, governance structures have moved towards multi-actor and multilevel institutional setups (cf. KAISER 2008) to suit open innovation forms and inter-organizational knowledge creation of the automotive industry. New organizations were directed to open up network relationships between different sectors to mobilize existing competences from different knowledge bases to create innovation platforms. Cluster policy was introduced not only in sectoral but also in cross-sectoral competence areas to promote combinatorial knowledge dynamics (Prognos 2009; Baden-Württemberg Ministry of Economics 2008). With the financial support of the European structural funds, particularly the EFRE (Europäischer Fonds für regionale Entwicklung) programme "innovation, knowledge based economy and cluster", state-wide networks and regional cluster initiatives have been promoted in the period 2007 to 2013.

Initiatives were not only driven by regional policy, but private businesses, as the following example of the Automotive Simulation Center Stuttgart (ASCS) shows. The center allows for the novel combination of highly specialized cumulative knowledge bases and is located in the Stuttgart region. Analytical knowledge from the field of mathematics and computer sciences was brought together with carriers of different synthetic knowledge bases within the application field of the automotive industry. Two underlying reasons drove the bottom-up initiative: On the one hand, the material and knowledge resources of the high-performance computing center had to be put to new uses, as companies were able to upgrade their own computing capacities at lower costs. On the other hand, new regulations in the fields of $\mathrm{CO}_{2}$ emissions, security and energy efficiency of automobiles called for a more extensive use of innovative simulation technologies.

After a two years stimulation and networking process, the ASCS was founded in 2008 by two automotive OEM from Baden-Württemberg, one German OEM and one supplier, service engineering firms, foreign hardware manufacturers and software companies but also the University of Stuttgart and semi-public organizations in the region. The latter brought in the experienced based knowledge of network and co-operation building to small and medium sized suppliers. The center had been financed from the start by member fees, and was only later supported by initial funding of the Baden-Württemberg Ministry for Science, Research and the Arts.

Bringing all these actors together was difficult, as a lot of trust was required. Especially software developers were cautious at first to cooperate with their competitors. Yet in parts, participating companies were familiar with each other from previous collaborations on the national level in this field of technology. The initiator was director of a national association focused on simulation technology in the automotive industry. His formerly built professional network relationships to experts with specialized synthetic knowledge bases allowed him access to a variety of potential partners on the national level, who were familiar with each other due to the work in the association. This familiarity was essential in building up trust amongst the partners.

\section{Extra-regional knowledge sourcing}

Furthermore, policy supported extra-regional knowledge interaction processes by taking part in transnational initiatives such as Bench Learning in Cluster Management for the Automotive Sector in European Regions (BeLCAR) or Clusterinitiative Automotive Region Stuttgart (CARS) (STRAMBACH/STOCKHORST/SANDMÜLLER 2009). The primary aim of CARS is the creation of linkages between existing regional, national and international networks and the network management. During the last years more than 300 companies and organizations participated actively in this initiative. The creation of international networks and the anchoring of international knowledge occurs through cooperation with leading cluster initiatives of the Eu- 
Fig. 1: Actors involved in the Automotive Simulation Center Stuttgart (ASCS)

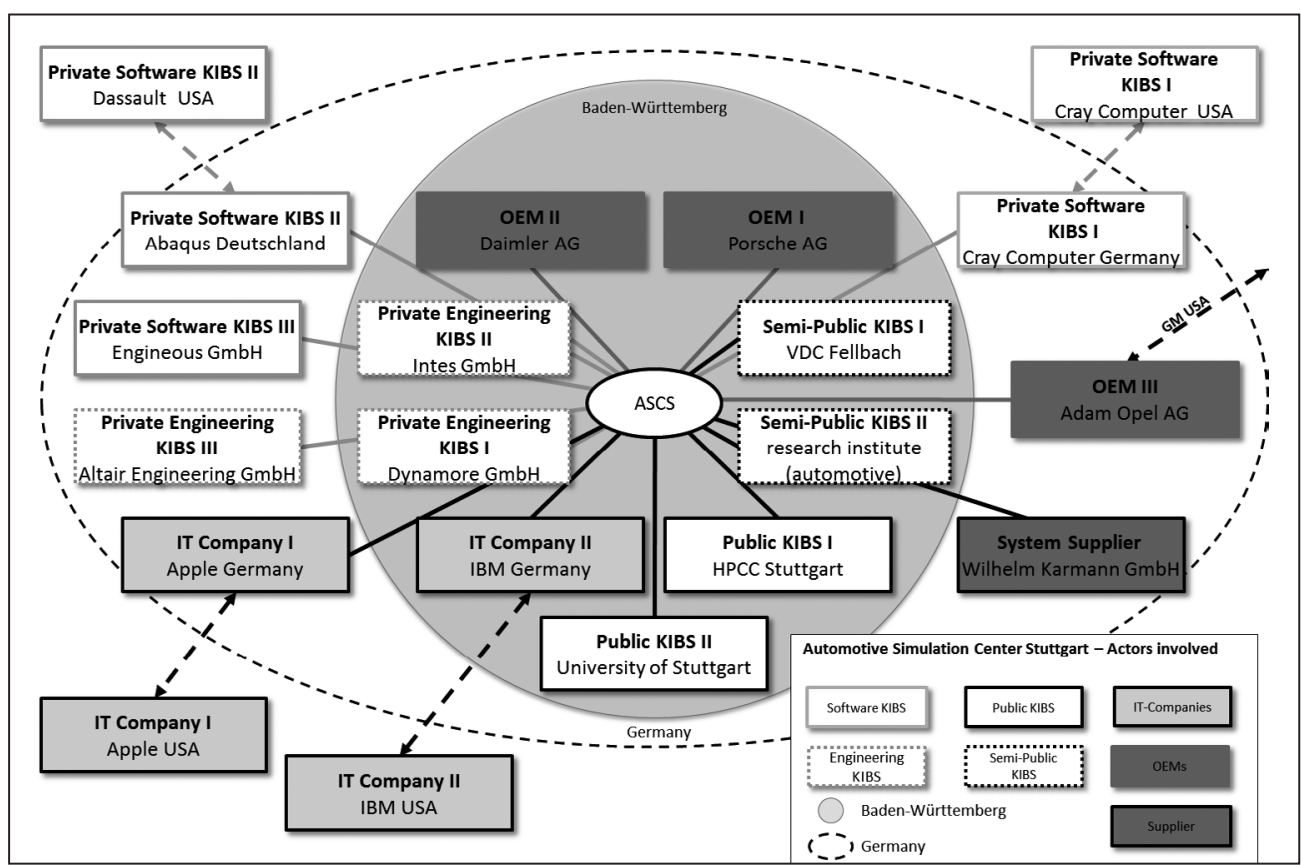

Source: own research

ropean automotive regions. These international linkages enable knowledge transfer and flow of knowledge concerning sector related trends, technologies and opportunities for scientific research as well as cooperation between companies. Among others, clean energies, sustainable mobility, software service for automotive industry or qualifications and skilling are subjects treated and discussed within communications platforms.

For the initiative BeLCAR, the regional development agency of the Stuttgart region collaborated with European regions (East England, Upper Austria, Lombardy, Catalonia and West Transdanubia) joined forces in order to improve the actions and innovative capacities of automotive clusters in Europe. The main objectives are the mobilization of existing automotive clusters in Europe to collaborate and exploit synergies as well as fostering exchange of knowledge and good practice between automotive clusters. Besides initiating joint projects, the cluster management organizations themselves are involved in distant learning processes which support the understanding of the success factors and weak- ness of clusters in the automotive sector through the exchange of experience-based knowledge (Grosz 2008).

Remarkably, these developments presented neither complete disruptions with the well-established structures of the cumulative knowledge bases which had proven to be successful, nor a rise of completely new actors, but a gradual reorganization of the institutional setting of the region. Nevertheless, they enhanced variety in the institutional setting which in turn diminished institutional inertia. Directly or indirectly these developments may have fostered dynamics within the path by opening up opportunities to explore complementary knowledge bases and contributed to the sustained success of the regional automotive industry.

\section{Methodology}

A qualitative research design was chosen in order to gain empirical insights into the nature of knowledge dynamics behind innovations in an inductive way. The empirical methods of data 
collection used a combination of secondary and primary research. Applied research heuristics were actor-focused, inspired by the actor centered institutionalism (MAYNTZ/SCHARPF 1995) and the SAS taxonomy (AsHeIM 2007). The secondary research used literature review, document and media analysis with the objective to analyze the restructuring process at the meso-level of the region and the industry. The primary research contained explorative as well as semi-structured interviews with corporations in the automotive industry and (semi)public organizations in Baden-Württemberg. All together, the empirical research is based on 23 qualitative interviews, of which four of these were conducted with regional (semi)public organizations.

In the empirical research a biographical method originally used in social sciences (WENGRAF/ Chamberlayne/Bornat 2002) was applied and adapted to explore combinatorial knowledge dynamics behind innovation. A detailed description of the innovation biographies as an empirical instrument is beyond the scope of the paper, but more information can be found in Butzin/Rehfeld/Widmaier (2012); ButZIN/WidMAiER (2012) and Strambach (2012). Such an approach has a main advantage in the reconstruction of time-space paths of knowledge interactions: It enables grasping the dynamism without being limited to certain geographical or sectoral scales. Every innovation is unique and in the focus of the biography is the innovation event itself or, in other words, a change process. By examining the entire life-span of an innovation, a biography captures the actors involved, their relationships, their knowledge contribution and their institutional and geographical settings. With a snowball sampling strategy the sequences in time, the distributed knowledge activities and different actors of the innovation event were investigated.

In this article one exemplary biographical case is presented to explore in depth the time-space path of the knowledge interaction processes. It comprises an innovation event of MEDIAKIBS, a firm providing services among others for clients in the automotive industry. This biography is based on four in-depth interviews lasting between one and a half and two hours. The empirical material was examined mainly by a deductive, theory-led coding strategy to built categories, supplemented by inductive ones formulated directly out of the material (BöHM
2001; KUCKARTZ 2010). For each phase of the innovation biography, the relevant types of knowledge brought in by different actors (using the SAS typology) and the different cumulative and combinatorial knowledge dynamics were identified alongside barriers to innovation, actors, actor constellations, their locations, and the type of collaboration.

\section{Knowledge combination on the micro- level}

Having outlined the structures and development path of the regional automotive industry, in the following we elaborate on combinatorial knowledge dynamics on the micro-level. On the basis of an in-depth case study we explore what enables and limits combinatorial knowledge production and how these processes contribute to dynamism within the path.

MEDIAKIBS is a service provider established in 1994 near Stuttgart, operated in various fields such as graphic animation and digital postproduction. After a period of serious crises the firm specialized in 3D-visualization for the automotive industry. Its products and services are mostly related to clients' marketing activities. In 2005, the acquisition of new clients - as described in the following case study - required a fundamental organization change during which the number of employees increased fivefold. Within a year, MEDIAKIBS was able to increase its staff from 12 to 60 employees. Today, the company employs 130 professionals located in Stuttgart, Munich, Detroit, Los Angeles, Hamburg and London. That is a remarkable change as MEDIAKIBS was a typical small size creative service provider like over $80 \%$ of the firms in this sector until 2005. For a long time the structure of the firm had remained the same and fluctuated around 12 employees, including two small subsidiaries in the automotive regions Munich and Detroit.

Closely interwoven with the organizational restructuring process was the development of a technological innovation - an automated content management tool that is in the focus of this case study. However, the reconstruction of the technological innovation event by means of a biographical method shows that without the simultaneous organizational change and the development of new routines the technological innovation could not have been developed. 
The technological innovation of the automated content management tool (ACM-box) allows for the standardization of visualization procedures and thus facilitates the management of large projects. Highly realistic digital computer models of automobiles can be integrated into any kind of photographic or cinematic environment. Furthermore, it accelerates the adaptation of marketing campaigns to different national or regional contexts by enabling quick editing of e.g. license plates and traffic signs.

This innovation can be characterized as the result of combinatorial knowledge dynamics, since its creation requires bringing together highly specialized cumulative symbolic and synthetic knowledge bases located in different sectoral and spatial contexts. The exploited knowledge bases that are tapped comprise on the one hand the symbolic, marketing-related knowledge base on how to present cars in different cultural markets to various target groups with distinct lifestyles, norms and values. In this knowledge domain the core competence of the MEDIAKIBS is located. On the other hand, there is the rather specialized technology-related synthetic knowledge base on the application of visualization technology and on the application of information technology and software tools to organize, handle and store very high data volumes. Furthermore the integration of specialized knowledge bases located in the domains of human resources management, firm and work organization was necessary to give birth to the innovation.

The biographical approach provides deeper insights in modes in which these combinatorial knowledge dynamics behind the innovation unfold in time and space. The central elements of the innovation biography as they appeared a posteriori, reconstructed from the empirical material, are mapped in Fig. 2. The chosen type of depiction should not mislead to think of innovation as a predefined linear sequence of events. Instead, in the course of the innovation situations emerged in which actors had to take decisions which were subject to uncertainties and challenges, leaving open the continuation and success of the project.

In 2006, the starting point for this innovative event was the search of an automotive OEM for

Fig. 2: Innovation biography of MEDIAKIBS's automated content management tool

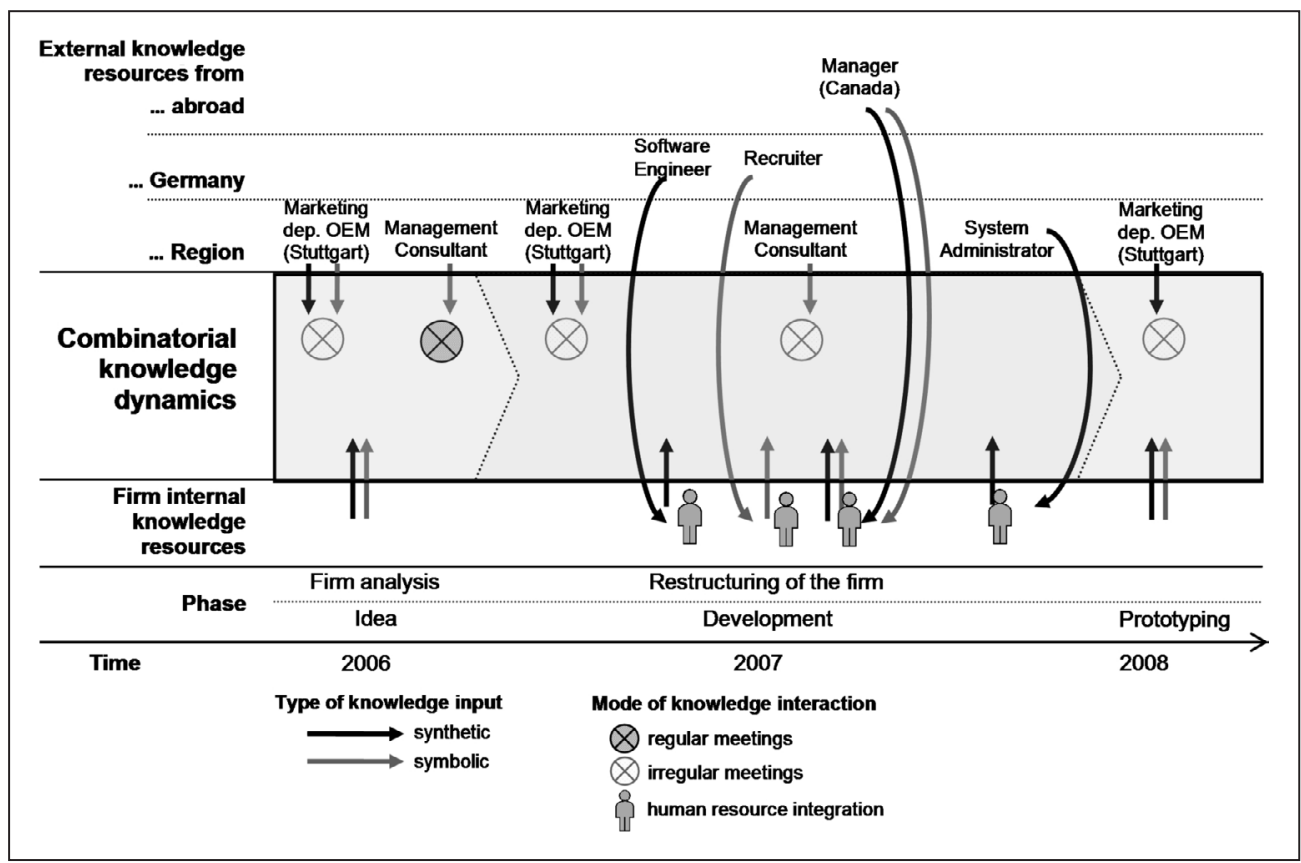

Source: own research 
a media partner to provide graphical material for a marketing campaign for the global launch of a new type of car (Fig. 2). Because of personal contacts between the CEO of MEDIAKIBS and the marketing department of the OEM this large scale contract could be acquired by MEDIAKIBS. Taking over this project was highly risky for MEDIAKIBS and the challenge was enormous. Previously the firm produced pictures and films, individually crafted in a creative way by so-called 3D-artists on their own without any division of labour: This kind of organizational routine is a common practice in many small size creative media firms. However, in the first stage of the project it became very obvious that the large-scale project could not be mastered by this mode of production in the scheduled time. The OEM project requested the production of 350000 high-quality photos, whereas previous projects usually comprised about five pictures.

In this critical situation the first phase of the innovation process started and an internal search was set off to find problem solutions. Yet the $\mathrm{CEO}$, while trained and highly-skilled in design, lacked the necessary knowledge about strategies to change the organizational structures or find technological solutions. Thus, an external management consultant from Baden-Württemberg was called in to support the analysis of the firm's routines and procedures.

During the following nine month a complex communication and learning processes took place. Several divergent interpretations and perceptions had to be overcome in order to create a common understanding on meanings of appropriate further actions. Knowledge exchange and trust building was facilitated by regular workshops and spontaneous meetings on site of the MEDIAKIBS. In these interaction processes thoughts and goals for a new business model were discussed and the idea to develop an automated content management tool (ACM-box) came up.

In this phase the moderation of the communication and learning processes by the consultant proved to be very important. He brought in his experience-based knowledge about organizational structures, processes and routines accumulated in various projects with clients from the local automotive industry. By introducing the logic of higher degree of specialization and modularization practiced for long time in knowledge using and creating activities of the automotive firms, the outline of a new business model gained clarity. Furthermore, the organizational routines in place in the automotive industry are often named product development process which structures knowledge creation processes in time. The consultant's knowledge on these routines also affected the organization of the technological innovation development process of the ACM-box. A rough concept was created on how to integrate this innovation process into the general change process of the firm's new structure.

At the end of this phase the decision was made to realize both the creation of the ACM-box and to change and introduce new organizational routines to approach the large-scale project from the client. However, some employees did not give up their skeptical attitude towards the planned restructuring. While used to work in several projects in an autonomous way with a high degree of freedom, the introduction of specialization and modularization were perceived as rather monotone and hindering creativity. Especially the 3D-artists who were integrated in the firm for the longest time most refused to realize the change. As divergent perceptions and cognitive distance could not be bridged some of them left the firm.

At this point in time the concrete process of routine changes was in large parts open. In the second phase the implementation of new routines and their further institutionalization into practices started. Several challenges had to be met in the organizational change process which meant upscaling of production and introduction of a higher degree of division of labour into the creative work processes. Many critical situations emerged, which could not be solved by internal knowledge resources. It required the integration of external human resources. Specialists in project management, business organization, system administration and personal management were sourced. The CEO's personal social networks played an important role in getting access to highly specialized professionals with complementary knowledge in these domains who were able to connect smoothly to the complex application contexts. The sourcing was not limited to Baden-Württemberg though: the new project manager came from Canada for instance.

The implementation of the new software tools brought with the possibilities to modularize working processes and standardization in differ- 
ent production steps going along with allowed for higher efficiency and higher output. The employees, originally called "3D-artists", now had to work on smaller parts in specialized production steps. These changes were enabled by the new project manager who had accumulated experience in the game industry, where the scaling of creative work is already more pronounced.

The change of organizational practices and the implementation of smaller specialized production steps connected with dynamic growth of the firm in one year from 12 to 60 employees contained many frictions. While the newly employed staff adapted the working processes smoothly some parts of the staff refused to practice the newly installed system that generated the need for many individual discussions. To overcome these problems new communication structures were initiated like regular meetings to generate mutual understanding and to convince the staff of the measures that had been taken.

Not only was the way of doing things altered by using a new technological solution, it implicated several adaptations in other organizational routines as well, affecting such diverse areas as even business culture. The main difficulty in this innovation process was not its technological nature, but the organizational change that went with it. However in the end, MEDIAKIBS was able to face the challenges and overcome these boundaries coming with combinatorial knowledge dynamics.

It enabled the company to evolve from a smallscale service provider to a technology provider working on a much larger scale. MEDIAKIBS's ability to combine its symbolic knowledge about marketing-related symbols and representations with synthetic knowledge on software technology in the visualization field appears to be responsible for the firm's present market success. In hindsight, the company might have stagnated or even lost business had it continued its ways of doing business. In the process clients from the automotive industry were provided with a new tool that can make the adaptation of global marketing campaigns to local consumer demands much more efficient.

\section{Discussion}

In the following it is discussed first how the institutional settings provided potential scope for combinatorial knowledge dynamics, secondly how participating actors managed to overcome boundaries in combinatorial knowledge dynamics, and thirdly how gradual institutional change can be observed in the exemplary case study of MEDIAKIBS and the development path of the automotive industry.

\section{The potential of institutional settings}

First of all, successful combinatorial knowledge dynamics require the existence of specialized cumulative knowledge bases that provide a potential scope for combination. It is essential in anticipating, understanding and exploiting opportunities for combination with other knowledge types. In line with ARTHUR's (2011) arguments on the evolution of technology, it can be stated that combinations of different knowledge types are not arbitrarily made, but require a sophisticated previous accumulation of specialized knowledge. For instance, for MEDIAKIBS the experience-based customer domain knowledge about the automotive OEM that the firm accumulated during several projects was essential to discover the need for the technological innovation and a new market that lead to initiate the combinatorial knowledge dynamics. The ASCS could build upon the expertise and experience of the computing center and its understanding of the special future demands for the application of simulation technology in the automotive industry.

Furthermore the social and personal networks provide a decisive potential to get access to highly specialized and spatially distributed but complementary knowledge bases. Combining knowledges is not restricted to the local sphere. Some complementary knowledge sources had to be sourced over geographical distance. During the innovation event, MEDIAKIBS had to enhance its knowledge base mainly by acquiring and integrating external human resources. The search for additional professionals and staff crossed regional and even national borders, mostly by the far-reaching social personal network of the CEO. His relational proximity to this globally spread highly-skilled persons enabled MEDIAKIBS to acquire new complementary knowledge in a phase characterized by high uncertainty and risk.

Moreover, organizational routines which link firms with their environment are embedded in regional institutional settings. As outcomes of 
collective localized learning processes routines are shaped by place specifities and cannot easily be replicated and transferred to other contexts. However, precisely this property incorporates a significant innovation potential. MEDIAKIBS is an example for the transformation and recombination of routines, developed and practiced in sectors with different dominant knowledge bases. The introduction of recombined routines in new application contexts enabled the innovation development.

Regarding the development of the regional automotive industry, actors reverted to institutional forms that have already been dominant parts of the institutional setting, such as associations and business networks to support complementary service industries. Political actors strategically aimed at combining peripheral elements of the institutional setting with the dominant path of the automotive industry. In the process they created cross-sectoral networks and organizations that bring together knowledge from various technological fields.

\section{Overcoming boundaries}

Overcoming boundaries posed by combinatorial knowledge dynamics and using the creative potential of cognitive diversity in a fruitful way requires the development of a mutual understanding. The use of temporary spatial proximity in a dynamic and situative way appears to be a decisive mechanism in the exploration of knowledge complementarities and the bridging of cognitive distances. Combinatorial knowledge dynamics are especially characterized by high uncertainties in the pay-off and the time horizon of their outcome, and require high investments to create mutual understandings between actors (STRAMBACH/KLEMENT 2012). Divergent interpretations and perceptions have to be overcome in order to create a common understanding on meanings of appropriate further social actions. As the innovation events reflect, temporary spatial proximity facilitated the establishment of relational proximity (IBERT 2010).

Furthermore, combinatorial knowledge dynamics apparently are neither limited to the local sphere, nor completely global affairs. We could observe in these cases (also see STRAMBACH/ KLEMENT 2012) that there is an interplay of local knowledge grounded in place-specific developments with globally sourced complementary knowledge. Both MEDIAKIBS and ASCS are involved in in-depth interactions with local automotive OEMs. From their demands the necessity and ideas for the described innovations were derived in the first place. Furthermore, local KIBS provided necessary knowledge inputs during the innovation process, especially in the case of MEDIAKIBS in which the external management consultant transferred knowledge on organizational routines gained in projects with clients from the local manufacturing industry to a new industry context.

On the meso-level, political actors in BadenWürttemberg already support the extra-regional sourcing of knowledge in various organizations aimed at supporting regional development, such as BeLCAR or CARS. In the case of the bottom-up initiative ASCS, remarkable efforts have been made towards bringing together most suitable participants. Where the required knowledge (e.g. regarding hardware companies) was not locally available, the initiative showed openness towards actors from beyond the border of Baden-Württemberg and Germany. Even though the ASCS aimed to impact the competitiveness of regional automotive companies, the spatial scope of the knowledge sourced is international. Limiting the initiative exclusively on local actors would have diminished its technological scope and possibilities.

\section{Gradual institutional change}

On the meso-level we can observe that the several challenges and adversities have been met by the creation of new institutional variety. These emerge in the form of new business networks or new organizations as collective actors with new competences. These new organizations are geared towards the fostering of peripheral elements of the dominant path of the automotive industry and the combination of existing knowledge bases within the region.

On the micro-level, in the case of MEDIAKIBS, the logic of organizational routines from the manufacturing industry was transferred to and recombined with routines used in the context of the media company, leading to a significant change in its business model formerly rooted only in the symbolic knowledge base. In the case of ASCS, an organization was transformed to enable actors from different sectors and stages of the value chain to work and conduct research in joint projects at the interface of the automotive and software industry. 


\section{Conclusions}

Not all types of knowledge exploration and exploitation processes generate the same need for institutional change. Innovations based on the combination of separated knowledge bases are characterized by small institutional overlaps between actors. Hence, in the process of overcoming boundaries due to a lack of cognitive and other types of proximities between actors, combinatorial knowledge dynamics drive organizational change. Innovating actors exploit path plasticity by intentional, creative actions, in which existing institutions are re-interpreted, adapted, transferred and new organizational routines and forms are created in the process. Thereby combinatorial knowledge dynamics can play an important role in the creation of dynamics within paths that diminish the risk of negative lock-in effects. Even though our analysis is limited to processes at the micro-level, it can be assumed that these provide an important mechanism for dynamics at the regional or sectoral level.

This paper argues that even though the technological dimension of combinatorial knowledge dynamics is challenging already, they imply even more challenging organizational change processes. Actors have to be capable of managing these change processes in the first place. This study was able to show that for the anchoring of combinatorial knowledge new organizational forms were built which in turn contribute to institutional variety and diversity in the path. Here there is a research potential to understand the fluid organization forms interconnected with knowledge combination. In the knowledge base literature distinct modes of creation, transformation, evaluation and exploitation of knowledge are already acknowledged. Yet even though these should correspond to distinct organizational routines, this stream of literature does not explicitly refer to them. Hence, the development and characteristics of specific routines that enable innovations based on the combination of differentiated knowledge bases are not analyzed in detail yet. This study is limited in its empirical basis and rather explorative in nature. Nevertheless the investigation of knowledge combination appears to be a fruitful area of research to enhance the understanding of regional development between path dependency and path plasticity.

Actors able to exploit path plasticity and drive combinatorial knowledge dynamics may con- tribute to regional and sectoral change processes by creating new organizational routines and forms. In direct or indirect ways these support dynamics and adaptiveness of an established path. The continuous success of the automotive industry in Baden-Württemberg shows that "for things to remain the same, things must change" (TOMASI DI LAMPEDUSA 1960).

\section{Notes}

1 The research was supported by the European Commission (integrated project EURODITE 006187), which is gratefully acknowledged. The authors would like to thank two anonymous referees for useful comments on an earlier version of the text.

2 Cognitions are broadly understood here as mental activities including perceptions, interpretations, sense making, knowledge and skills, norms and values which are developed by people in interaction with their social and physical environment (cf. BERGER/LUCKMANN 1966).

\section{References}

Amin, A./ Cohendet, P. (2004): Architectures of knowledge. Firms, capabilities, and communities. Oxford.

Arthur, W.B. (2011): The nature of technology. What it is and how it evolves. New York.

AsHeIM, B. (2007): Differentiated knowledge bases and varieties of regional innovation systems. In: Innovation, (20)3, 223-241.

Asheim, B. / Coenen, L. (2006): Contextualising regional innovation systems in a globalising learning economy: On knowledge bases and institutional frameworks. In: Journal of Technology Transfer, (31), 163-173.

Asheim, B. / GerTLER, M.S. (2005): The geography of innovation: Regional innovation systems. In: Fagerberg, J./ Mowery, D. C. / Nelson, R. R. (Eds.): The Oxford Handbook of innovation. New York, 291-317.

Baden-Württemberg Ministry of Economics (2008): Regional Clusteratlas. Stuttgart.

Becker, M.C. (2004): Organizational routines. A review of the literature. In: Industrial an Corporate Change, (13)4, 643-677.

Becker, M. C. / Knudsen, T. / March, J. G. (2006): Schumpeter, Winter and the sources of novelty, (15)2, 353-371.

Berger, P. / Luckmann, T. (1966): The social construction of reality. New York.

BöHM, A. (2001): Theoretisches Codieren. Textanalyse in der Grounded Theory. In: Flick, U. / Kardoff, E. / Steinke, I. (Eds.): Qualitative Forschung. Ein Handbuch. Reinbek bei Hamburg, 475-485.

Boschma, R.A. (2005): Proximity and innovation: A critical assessment. In: Regional Studies, (39)1, 61-74. 
Boschma, R.A./Frenken, K. (2011): The emerging empirics of evolutionary economic geography. In: Journal of Economic Geography, (11)2, 1-13.

BraczyK, H.-J./ Schienstock, G. / StefFensen, B. (1996): Die Regionalökonomie Baden-Württembergs. Ursachen und Grenzen des Erfolges. In: Braczyk, H.-J. / Schienstock, G. (Eds.): Kurswechsel in der Industrie? Lean Production in Baden-Württemberg. Stuttgart, 24-51.

Butzin, A./ Rehfeld, D. / Widmaier, B (2012): Innovationsbiographien. Räumliche und sektorale Dynamik. Baden-Baden.

Butzin, A. / Widmaier, B. (2012): The study of time-space dynamics of knowledge with innovation biographies. (= Working Paper on Innovation and Space, 07/12).

CAMpBELl, J.L. (2011): Institutional reproduction and change. In: Morgan, G. et al. (Eds.): The Oxford Handbook of Comparative Institutional Analysis. Oxford, 87-115.

CArlile, P. R. (2004): Transferring, translating, and transforming: an integrative framework for managing knowledge across boundaries. In: Organization Science, (15)5, $555-568$.

CAsper, S. / Hollingsworth, J.R./WhitLey, R. (2005): Varieties of capitalism: Comparative institutional approaches to economic organization and innovation. In: Casper, S. / Van Waarden, F. (Eds.): Innovation and institutions. A multidisciplinary review of the study of innovation systems. Cheltenham, 193-228.

Cooke, P. / Heidenreich, M. / Bracyzk, H.-J. (2004): Regional innovation systems: The role of governances in a globalized world. London.

Crevoisier, O./JeAnNerat, H. (2009): Territorial knowledge dynamics. From the proximity paradigm to multilocation milieus. In: European Planning Studies, (17)8, $1223-1241$.

Dosi, G. / Faillo, M. / Marengo, L. (2008): Organizational capabilities, patterns of knowledge accumulation and governance structures in business firms. An introduction. In: Organizational Studies, (29)8-9, 1165-1185.

FORAY, D. (2004): Economics of knowledge. Cambridge, MA.

Fuchs, G. / Wassermann, S. (2005): Path dependency in Baden-Württemberg. Lock-in or breakthrough? In: Fuchs, G. / Shapira, P. (Eds.): Rethinking regional innovation and change. Path dependency or regional breakthrough. New York, 232-248. (Economics of Science, Technology and Innovation, Vol. 30).

Grabher, G. (1993): The weakness of strong ties. The 'Lock-in' of regional development in the Ruhr Area. In: Grabher, G. (Ed.): The embedded firm. On the socioeconomics of industrial networks. London, 255-277.

Grant, R.M. (1996): Prospering in dynamically-competitive environments. Organizational capability as knowledge integration. In: Organization Science, (7)4, 375-387.

Grosz, A. (2008): Automotive clusters in the BeLCAR project. An analysis. Győr. (West Hungarian Research Institute of CRS HAS)

HALKIER, H. (2012): Knowledge dynamics and policies for regional development: Towards a new governance paradigm. In: European Planning Studies, (20)11, 1759-1766.
HASsinK, R. (2010): Locked in decline? On the role of regional lock-ins in old industrial areas. In: Boschma, R./ Martin, R. (Eds.): The Handbook of Evolutionary Economic Geography. Cheltenham, 450-468.

HaWlitscheK, A. (2011): 125 Jahre Automobil. Bedeutung der Automobilindustrie für die Wirtschaft Baden-Württembergs im Spiegel der Umsatzsteuerstatistik. Stuttgart. (Statistisches Monatsheft Baden-Württemberg, 10/2011).

Heidenreich, M. / Krauss, G. (1998): The Baden-Württemberg production and innovation regime. Past successes and new challenges. In: Braczyk, H.-J. / Cooke, P. / Heidenreich, M. (Eds.): Regional innovation systems. London, 186-213.

IBERT, O. (2007): Towards a geography of knowledge creation. The ambivalences between 'knowledge as an object' and 'knowing in practice'. In: Regional Studies, (41)1, 103-114.

IBERT, O. (2010): Relational distance. Sociocultural and time-spatial tensions in innovation practices. In: Environment and Planning, (42)A, 187-204.

KAISER, R. (2008): Governance and the knowledge economy. Relevance and potentialities of the "analytical governance concept" within the EURODITE project. Hamburg.

KINDER, S. / RADWAN, L. (2010): Arbeit an der Routine. Zum Passungsverhältnis zwischen organisationalen Routinen und ihrem territorialen Umfeld. In: Geographische Zeitschrift, (98)1, 41-59.

Knoeben, J./ Oerlemans, L.A. G. (2006): Proximity and inter-organizational collaboration: A literature review. In: International Journal of Management Reviews (8)2, 71-89.

Kogut, B./Zander, U. (1992): Knowledge of the firm, combinative capabilities, and the replications of technology. In: Organization Science, (3)2, 383-397.

Krauss, G. (2008): Baden-Württemberg als Prototyp eines regionalen Innovationssystems. Eine organisationssoziologische Betrachtungsweise. In: Blättel-Mink, B./Ebner, A. (Hrsg.): Innovationssysteme: Technologie, Institutionen und die Dynamik der Wettbewerbsfähigkeit. Wiesbaden, 229-248.

KUCKARTZ, U. (2010): Einführung in die computergestützte Analyse qualitativer Daten. Wiesbaden.

Mahoney, J./Thelen, K. (2010): A theory of gradual institutional change. In: Mahoney, J./Thelen, K. (Eds.): Explaining institutional change, 1-37.

Malerba, F. (2005): Sectoral systems of innovation. How and why innovation differs across sectors. In: Fagerberg, J./ Mowery, D. C. / Nelson, R. R. (Eds.): Handbook of Innovation. New York, 380-406.

Malerba, F. / Orsenigo, I. (2000): Knowledge, innovation activities and industrial evolution. In: Industrial Corporate Change, (9)2, 289-314.

MANNICHE, J. (2012): Combinatorial knowledge dynamics. On the usefulness of the differentiated knowledge bases model. In: European Planning Studies, (20)11, 1823-1841.

MAYNTZ, R. / ScharpF, F. (1995): Gesellschaftliche Selbstregelung und politische Steuerung. Frankfurt am Main/ New York

NonAKA, I. / TAKEUCHI, H. (1995): The knowledge creating company. New York. 
Nooteboom, B. (2010): A cognitive theory of the firm. Learning, governance and dynamic capabilities. Cheltenham.

PAVITT, K. (1984): Sectoral patterns of technical change. Towards a taxonomy and a theory. In: Research Policy, (13), 343-373.

PeliKan, P. (2003): Bringing institutions into evolutionary economics: another view with links to changes in physical and social technologies. In: Journal of Evolutionary Economics, (13), 237-258.

POLANYI, M. (1985): Implizites Wissen. Frankfurt am Main.

Prognos AG (2009): Analytische und konzeptionelle Grundlagen zur Clusterpolitik in Baden-Württemberg. Im Auftrag des Wirtschaftsministeriums des Landes BadenWürttemberg. Basel.

SChumpeter, J.A. (1934): The theory of economic development. Cambridge, MA.

Statistik der Bundesagentur für Arbeit (2012): Arbeitsmarkt in Zahlen. Sozialversicherungspflichtig Beschäftigte nach Wirtschaftszweigen (WZ 2008), Land Baden-Württemberg (Stichtag 31. Dezember 2011). Frankfurt am Main. (Arbeitsmarkt in Zahlen - Beschäftigungsstatistik).

STEHR, N. (1994): Arbeit, Eigentum und Wissen. Zur Theorie von Wissensgesellschaften. Frankfurt am Main.

Strambach, S. (2002): Change in the innovation process. New knowledge production and competitive cities. The case of Stuttgart. In: European Planning Studies, (10)2, 215-231.

STRAMBACH, S. (2008): Knowledge-intensive business services (KIBS) as drivers of multilevel knowledge dynamics. In: International Journal of Services Technology and Management, (10)2-3-4, 152-174.

Strambach, S. (2010): Path dependence and path plasticity. The co-evolution of institutions and innovation. The German customized business software industry. In: Boschma, R. / Martin, R. (Eds.): The Handbook of Evolutionary Economic Geography. Cheltenham, 406-431.
Strambach, S. (2012): Knowledge dynamics and knowledge commodification of KIBS in time and space. In: Di Maria, E. / Grandinetti, R. / Di Bernado, B. (Eds.): Exploring knowledge-intensive business services. Knowledge management strategies. Basingstoke, 56-78.

Strambach, S./Halkier, H. (2013): Reconceptualising change. Path dependency, path plasticity and knowledge combination. In: Zeitschrift für Wirtschaftsgeographie, (57) 1-2, 1-14. (Editorial to the special issue).

Strambach, S. / Klement, B. (2012): Cumulative and combinatorial micro-dynamics of knowledge. The role of space and place in knowledge integration. In: European Planning Studies, (20)11, 1843-1866.

Strambach, S. / Stockhorst, J. / SANDMÜller, M. (2009): Territorial knowledge dynamics in the automotive industry of Baden-Württemberg. The contribution of engineering services and visual computing services. EURODITE: Regional trajectories to the knowledge economy - a dynamic model. Marburg. (Research report, Reference No. D5e).

Strambach, S./Storz, C. (2008): Pfadabhängigkeit und Pfadplastizität von Innovationssystemen. Die deutsche und japanische Softwareindustrie. In: Deutsches Institut für Wirtschaftsforschung (Hrsg.): Nationale Innovationssysteme im Vergleich. In: Vierteljahreshefte zur Wirtschaftsforschung, (77)2, 142-161.

Teece, D. J./ Pisano, G. / Shuen, A. (1997): Dynamic capabilities and strategic management. In: Strategic Management Journal, (18)7, 509-533.

TeEce, D. J. (2010): Technological innovation and the theory of the firm. The role of enterprise-level knowledge, complementarities, and (dynamic) capabilities. In: Hall, B.H./ Rosenberg, N. (Eds.): Handbook of the Economics of Innovation. Amsterdam, 679-730.

Tomasi di LAmpedusA, G. (1960): The Leopard. New York. Wengraf, T. / Chamberlayne, P. / Bornat, J. (2002): A biographical turn in the social sciences? A British-European view. In: Cultural Studies - Critical Methodologies, (2)2, 245-269. 